\title{
An Evaluation of Australian and Swiss E-Shops in the Grocery Sector
}

\author{
Sherah Kurnia \\ Department of Information Systems \\ The University of Melbourne \\ sherahk@unimelb.edu.au
}

\author{
Uwe Leimstoll* \\ Petra Schubert* \\ * University of Applied Sciences (FHBB) \\ Basel, Switzerland \\ uwe.leimstoll@fhbb.ch; petra.schubert@fhbb.ch
}

\begin{abstract}
The Extended Web Assessment Method (EWAM) is an evaluation tool specifically created for the assessment of electronic commerce applications. The method is based on an evaluation grid that includes a set of criteria with which to appraise the quality and success of e-commerce applications. The focus is on consumer perspectives and the specific features of the Internet as a medium. In this paper, we used the EWAM tool for a comparative analysis of Australian and Swiss e-shops selling grocery products. Using a comparative study between two different countries, we explored patterns for success or failure of such online applications. In general, the findings show that web sites in both countries do not fully meet the expectations of consumers. General expectations of consumers in online grocery shopping were explored and highlighted in this study.
\end{abstract}

\section{Introduction}

The Internet has been increasingly used to facilitate online business transactions, not only between different business entities, but also between business entities and consumers. In the area of Business-to-Consumer (B2C) electronic commerce, the Internet is commonly used by businesses in various sectors to reach consumers online. Anecdotal evidence indicates that there has been a growing interest in online shopping in many regions, notably in the United States, United Kingdom, Europe and Australia $[1,2]$. Online shopping has many potential benefits to consumers, particularly in terms of convenience and time saving. In addition, the retailers will ultimately reap significant benefits as it will lead to more efficient use of personnel and simplification of building infrastructure [2].

While it appears to be easy for businesses to have an online presence facilitated by the Internet, many online businesses could only last for a short period [3]. As a matter of fact, there are many factors that need to be addressed carefully in order to successfully operate an online business. Apart from business model, value proposition and organizational set-up, one of the most important factors is the overall design of the web site as the primary interface with the consumer in electronic commerce. Consumers need to feel comfortable and confident with the online systems, from getting the information about the products, ordering, paying, tracking to receiving the products $[1,4]$. Nevertheless, few Internet merchants have ever tried to assess their web sites from a consumer perspective to reveal weaknesses and trigger improvements.

In this paper, we demonstrate the usefulness of evaluating web sites based on the perception of consumers in order to identify their strengths and weaknesses. Our objective is to assist practitioners to develop better online shops. For this purpose, the Extended Web Assessment Method (EWAM), an evaluation tool was employed [6]. When starting our work we realized that there exists a variety of different approaches for Web site evaluation [e.g. 5, 6, 7]. In 2002, there even was a (double) Special Issue on "measuring e-commerce net-enabled organizations" in the Information Systems Research Journal [8, 9, 10]. In the end, EWAM seemed to be the most suitable for our needs. The method comes with teaching material for instructors, builds on the classic transactions phases which are usually an integral part of E-Commerce syllabi, and provides a tool for online data collection and a graphics report. The current version of EWAM is widely used in research, teaching, and consulting. In this study, we evaluated a number of Swiss and Australian web sites in the grocery sector with the tool. This study is part of a larger-scale project which attempts to compare the maturity level of web sites in different countries.

In the next section, we provide basic description of the Extended Web Assessment Method (EWAM) tool, including the theoretical background, data collection and data analysis procedures. We then describe the web assessment conducted in this study and present selected findings. Finally, we discuss the comparative analysis and draw conclusions.

\subsection{The Extended Web Assessment Method (EWAM)}

The Web Assessment Method has already been used for a couple of years $[18,19,20]$ and has been statistically tested with empirical data [5]. It is a sound method based 
on scientific principles but also oriented to offer e-shop operators advice for improvement of their services. The method defines an evaluation grid with a set of criteria for appraising the quality and success of existing e-commerce applications. In addition to a rigorous focus on consumer perspectives, success in implementing an offer of products and services is considered with reference to the specific features of the electronic medium.

The Web Assessment Model examines the three classic transaction phases of electronic markets, which include information, agreement, and settlement phases. A fourth element, the community component, is integrated as a link between the actual purchase transaction and the necessary trust relationship in the virtual realm. Where marketing aspects are concerned, the Web Assessment Model focuses on the special features inherent in the Internet.

The Web Assessment Method, developed in 1997, represents a step toward an all-embracing evaluation of ecommerce applications from the customer's point of view. The method was fundamentally revised in the summer of 2000. Besides taking account of new research findings, especially in the Internet marketing field, it also incorporated the Technology Acceptance Model established for the acceptance of information systems [11].

\subsection{Evaluation Criteria}

The Extended Web Assessment Method defines an evaluation grid made up of a set of criteria with which to appraise the quality and success of e-commerce applications. A successful e-commerce application must meet the needs of the user in accordance with "Perceived Usefulness" (Criteria USEF1-USEF15) and "Ease of Use" (Criteria EOU1-EOU8). Under the headword "Trust" (Criteria TRUST1-TRUST2), questions about the subjective norm [7] are also taken into account. Trust is the sine qua non of e-commerce, for business will not be transacted in situations where there is no trust. A success or quality feature must be assigned to one of these categories. The list of criteria can be found online [http://ebusiness.fhbb.ch/survey/ewam.nsf/assessmenten]. Evaluation of an e-commerce application with EWAM begins by assigning the concerned web site to a sector. During evaluation, the reference sector for benchmarking will be identified.

The success and quality criteria are formulated in general terms and are valid in every sector, but are differentiated by their importance ratings. In order to take due account of the differences between the individual sectors, criteria are given weights corresponding to the different sector profiles and their relevance in the sector. Thus, for instance, being up to date with information is of greater importance for a supplier of financial information (e.g., stock brokerage, real-time share prices) than for a supplier of consumer goods. On the other hand, the choice of ge- neric services (EOU 5) (e.g., tracking a parcel) is of lesser importance for an enterprises that distributes digital goods (e.g. software) than for one that delivers books. Specific and high-quality analyses necessitate precise recording of the level of importance per criterion and per sector. The importance per criterion is recorded on a scale of "unimportant" $(-2)$, "less important" $(-1)$, “important" $(+1)$, and "very important" (+2).

An EWAM criterion is first assigned to a criteria category ("Ease of Use," "Usefulness," or "Trust"). Within these three categories the criterion is allotted to one of the four transaction phases of electronic markets (information, agreement, settlement, and after-sale), to the community component, or to the category "Final Section" which concerns all phases.

Like ServQual [13], an instrument for assessing service quality, EWAM is based on a double evaluation for each criterion. Figure 1 shows the two steps of an evaluation. In the first step, the assessor declares the subjective importance of an attribute. The next step is an evaluation of all the web sites in the concerned sector. The aggregation of the importance ratings of the assessors (Step 1) is an important prerequisite for the generation of results. In cases where importance is low (-2), the actual evaluation values (Step 2) are almost annihilated. The lower the importance value of a criterion, the smaller the impact of this attribute on the overall score. Unlike ServQual, where each of the two questions is compared for every single assessor, EWAM aggregates the importance ratings for multiplication with the evaluations. This procedure has the advantage of leveling out extreme values for expectations and taking into account the different experience levels of the assessors.

\subsection{The EWAM Tool: data collection and analysis}

Data are collected over the Internet with an online questionnaire (the EWAM tool). An assessor conducting an evaluation with the EWAM tool begins by recording the URL of the web site under examination and assigning it to a sector. The scale of the possible choices is so arranged that the assessor must decide on a positive or negative statement with each value. The scale has four values $(+2,+1,-1,-2)$. The alternative value "N/A" (i.e., not applicable) can be used if a criterion is not relevant or not available in a particular context. The criteria are formulated in such a way that a positive (negative) evaluation will lead to a positive (negative) result. "I strongly agree" always scores +2 , "I slightly agree," +1, "I slightly disagree," -1, and "I strongly disagree," -2. "N/A" scores zero, which is disregarded in further calculations (e.g. averages). The criterion "Cost benefits passed on to the client (USEF2)" can only be evaluated when the business has a physical counterpart where prices are different from the prices offered on the web site. 


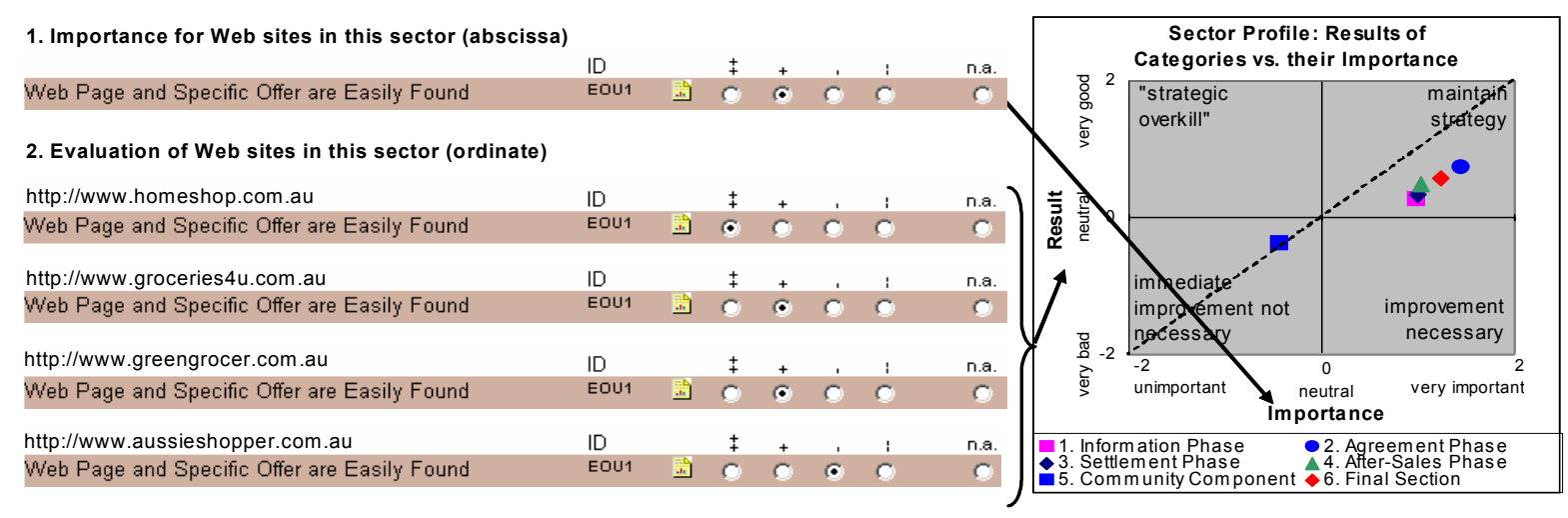

Figure 1. Two-Step Assessment: (1) Importance Rating, (2) Web Site Evaluation

In data analysis, the EWAM tool defines three profiles for drawing up meaningful evaluations of any web site under examination:

- Sector Profile: the profile of the relevant sector.

- Company Profile: the profile of the web site.

- Best Practice Profile: the profile of the best of breed in the relevant sector.

The web site of interest (company profile) can then be compared to the sector average, to the best practice profile, or to one of its competitors.

EWAM judges web sites purely from the customer's point of view. Thus a web site that obtains the best EWAM result is not necessarily the most successful in financial terms, since success is influenced by other factors such as e-business relevance of the offer, profitability, backend integration, and financing aspects. A best practice profile can only be established when (1) a sufficient number of different Internet businesses per sector have been evaluated, and (2) these have been compared with their success in the real world. Accordingly, an adequate best practice data reference base can only ensue from the combination of points (1) and (2).

\subsection{Personal Web Assessment Report}

Based on the web site assessment, a Personal Web Assessment Report that contains the following analyses and graphical representations is produced:

1. Summary of individual criteria and results in the categories "Information Phase," "Agreement Phase," "Settlement Phase," "After-sale Phase," "Community Components," "Final Section," and calculation of the total score.

2. Comparison of the web sites examined with the sector average and the sector best practice in a quantitative and graphical analysis, taking no account of the importance ratings of the criteria.
3. Graphic comparison of the results of six categories (1, 2 ) with the importance ratings for company and sector profiles.

4. Comparison as in (2) above, but taking full account of the importance ratings of the criteria.

\section{The Web Assessment Study of the Swiss and Australian Grocery Sector}

The participants of this study were students enrolled in Electronic Commerce classes at the University of Melbourne, Australia and the University of Applied Sciences Basel, Switzerland in the year 2003 and 2002 respectively. In Australia, each web site to be evaluated was assigned to four tutorial classes. A tutorial class consisted of 20 students on average. In Switzerland, there was only one class of 25 students where each student evaluated all four web sites. Although the participation was voluntary, we encouraged the students to perform the evaluation since the participation meant extra practice in preparation for a subsequent assignment. The number of responses for the web sites varied from 5 to 56 . Although for a few web sites the number of participants was quite low, a subsequent qualitative evaluation by the authors revealed the plausibility and usefulness of the results.

For the evaluation of the web sites, the students used the EWAM tool, as described in the previous section. Before the evaluation process started, the students were thoroughly instructed in the use of the tool. The training of the assessors is an important learning process that confronts them with the basics of high-quality e-commerce services. Data were submitted by the students online and analyzed centrally by the authors. For each web site, a personal web assessment report was produced. Specific sector assessments compare companies in the same sector against one another. 


\section{Importance Ratings}

In this section, we first examine the importance of categories for the grocery sector as rated by the participants in Australia and Switzerland (Table 1). Six web sites for the grocery sector were assessed in Australia and four web sites in Switzerland. Details of these sites are provided in the next sub section. The rating is based on a four point scale: from unimportant (-2) to very important $(+2)$.

The results show that the perceived importance of criteria for both countries is very similar and that all phases except for the community component were perceived to be important. A closer look at the results reveals that the Accessibility of the web site, Structure of the Contents, Quality of Information and Price Benefits are important criteria which the participants emphasized for the Information Phase. Other items including Ordering Procedure, Tracking and Tracing, and Access to Customer Support were found to be crucial in the Agreement, Settlement and After-Sales Phases, respectively. In addition, the Availability of the System, the Design of the User Interface and the Trustworthiness were also cited as important by most participants.

Table 1. The Importance of Each Category Used in the Study

\begin{tabular}{|l|c|c|}
\hline & \multicolumn{2}{|c|}{$\begin{array}{c}\text { Importance Grocery } \\
\text { (Range: -2/+2) }\end{array}$} \\
\hline Phase/Component & Australia & Switzerland \\
\hline 1. Informaton Phase & 0.97 & 0.84 \\
\hline 2. Agreement Phase & 1.44 & 1.50 \\
\hline 3. Settlement Phase & 0.99 & 0.59 \\
\hline 4. After-Sales Phase & 1.02 & 1.38 \\
\hline 5. Community Component & -0.44 & -0.88 \\
\hline 6. Final Section & 1.23 & 1.13 \\
\hline
\end{tabular}

The above findings suggest that customers or users in general have a high quality expectation towards the web sites in the grocery sector. The main reason for this might be the novelty of buying groceries online which results into a perceived uncertainty that is still high $[1,14]$. Consumers are very sensitive to ordering groceries online since there is a high chance of not getting the grocery items in the expected quality, especially for perishable products such as fruit and vegetables [1]. This is consistent with the findings of previous studies exploring the slow uptake in online grocery shopping adoption in a number of regions $[15,16]$. Consequently, items such as trustworthiness were rated paramount and significantly more important than for example in a different study of the book retail industry.

Furthermore, the Agreement Phase is perceived to be more important in the grocery than in other sectors with the order procedure being especially important. Grocery shopping involves searching and selecting a comparatively large number of products. A smart and easy-to-use order procedure that supports the customer in making selections and filling the shopping cart is thus crucial for a satisfactory shopping experience. On the other hand, our study shows that the availability of recommendation systems is more important for other than grocery items, which is not surprising given that groceries are every day items with a rather stable need. In the same way, the community component is perceived to be not so important for the grocery sector.

\subsection{Australian Results}

Six Australian web sites were found to be operational at the time of this study. They included:

- http://www.homeshop.com.au

- $\quad h t t p: / / w w w . g r o c e r i e s 4 u . c o m . a u$

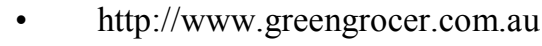

- http://www.aussieshopper.com.au/

- http://www.shopfast.com.au/

- http://www.colesonline.com.au/

Figure 1 depicts the summary of the overall evaluation of the six web sites. The score is based on a four-point scale: from -2 : very bad to +2 : very good. As shown in the figure, Colesonline appears to be the best site in the sector, whereas Groceries4U web site has the worst evaluation result. Other web sites require significant improvements in order to achieve a comparable quality web site as Colesonline, which is the best practice web site in this sector.

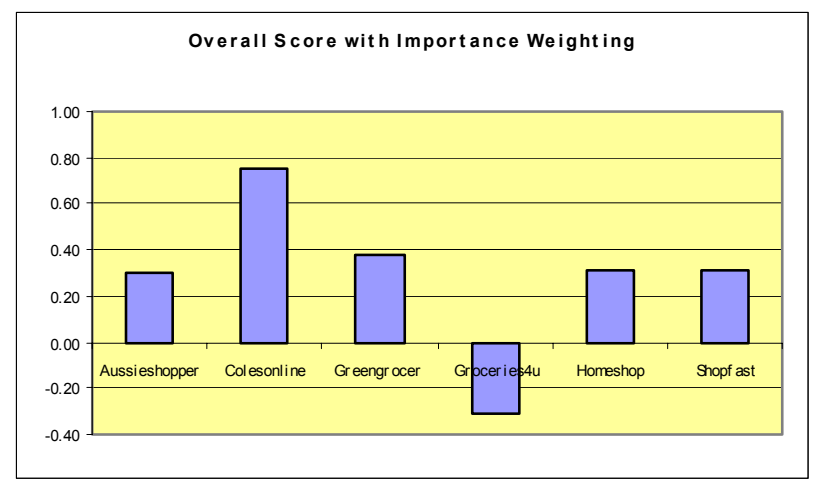

Figure 1. The Summary of the Overall Web Evaluation (Australia)

Figure 2 summarizes the company profile for all web sites evaluated in this study, indicating the score obtained in each phase. It shows that the Best Practice Company was rated much higher than other companies in most of the categories involved in this study, particularly in the Agreement Phase, After Sales Phase and the Final Section. The performance of other sites evaluated varies across all categories. For these web sites, the highest score was obtained for the Agreement Phase and the Final 
Section, but it was scored less than one by the participants. Thus, most participants were not satisfied with these sites in general. These observations were confirmed by the subsequent qualitative analyses conducted by the authors, as discussed below.

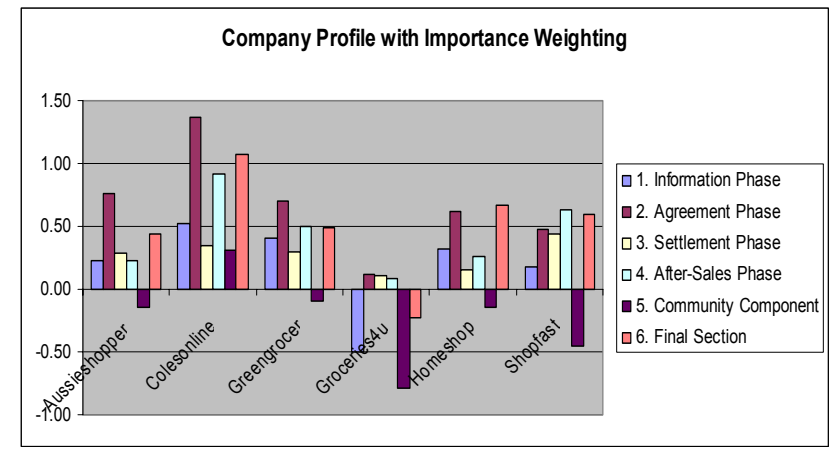

Figure 2. Summary of the Company Profile (Australia)

Firstly, from the qualitative analysis, it was found that Colesonline, as the best practice, has a pleasant user interface with information about various aspects (for example items on specials, clearance aisle, information and support, payment and pricing policy) organized in a logical way. Furthermore, the use of hypermedia to describe products is consistent and appropriate. In addition, the site enables consumers to make use of their experience in shopping at the physical supermarket by organizing products by aisles. Therefore, most assessors gave a relatively high rating for most of the criteria in the Information Phase of Colesonline. Groceries $4 \mathrm{U}$, on the other hand, contains too much information on its main page, which is not necessarily important for consumers to know before starting to shop online. Moreover, the arrangement of the information on the site is inconsistent and confusing. Besides, many pictures that describe the products are not available. Furthermore, the use of flashing images to indicate new items can be irritating to some consumers. All this provides further explanation of why most of the assessors were unsatisfied with Groceries $4 \mathrm{U}$ in the Information Phase.

For the Settlement Phase, the subsequent qualitative analysis discovered that the ordering procedure actually highlights the strength of Colesonline. The web site provides consumers with a very clear procedure. The 'Buy' button is located next to each item and the 'Shopping Basket' is always apparent to consumers, so that they can fill in or modify the quantity of each product as required in case of a change of mind during the process. This provides an additional explanation of why Colesonline received the highest rating for the Settlement Phase. At the other extreme, the analysis discovered that Groceries $4 \mathrm{U}$ particularly frustrates consumers due to its unclear ordering procedure. One of the ways to put items in the shopping basket is by entering the quantity for the products they wish to buy from the list of products and then clicking the 'Buy' button. This button, however, may not be apparent to consumers if the list is long since it is located far at the bottom of the list. Likewise, the 'Shopping Basket' is not readily viewable to consumers, since they need to click on the 'Go to Shopping Cart' button that is also located at the bottom of the list of products. Finally, with this approach of selecting products, the shopping trolley will not be updated instantly, which is likely to confuse the consumers. This suggests that Groceries $4 \mathrm{U}$ needs to undertake major improvements in the Agreement Phase.

In the Settlement Phase, the results of the assessment demonstrate that Colesonline is no longer taking the lead. The qualitative analysis discovered that all web sites actually allow customers to pay using mobile EFTPOS and online payment with credit cards or customer account. In addition to these methods of payment, AussieShopper also allows customers to pay with cash or cheque upon delivery. Besides, unlike other websites, it enables customers to track and trace their orders by providing the contact number of the drivers. This provides an explanation of why AussieShopper was rated favorably for the 'Integration of Generic Service' and 'Tracking and Tracing' criteria in this phase compared to other web sites. However, no explanation obtained from the analysis could explain why Colesonline received the lowest rating for the 'Tracking and Tracing' criterion.

For the After-Sales Phase, the qualitative analysis revealed that while other web sites simply provide the company contact details to deal with any enquiries from customers, Colesonline actually established what is called the 'Customer Care Centre'. This is intended to help customers with any queries regarding Colesonline. It offers customers with the best technical and non-technical assistance possible through their trained staff. A contact number as well as the details of the opening hours of the Customer Care Centre are provided. This increases the confidence of consumers in the accessibility and performance of customer support provided by Colesonline. Therefore, Colesonline was rated high in the After-Sale Phase. Similar to the findings in the previous phases, Groceries $4 \mathrm{U}$ was given the lowest rating in this phase. The possible explanation for this from the subsequent analysis conducted was that Groceries $4 \mathrm{U}$ has various contact persons and numbers to deal with general enquiries, customer service, and technical assistance and there is no information on their availability. This may reduce the confidence of consumers in terms of the accessibility and performance of the customer support that does not seem to be well integrated. Other web sites have a stable performance in this phase as they provide reasonable customer support details.

Finally, for the Final Section, Colesonline once again received the highest rating. Many of the issues discussed in the Information and Agreement Phases are related to the last phase. The analysis also discovered that the performance of Colesonline and Shopfast in this section is very comparable and therefore some assessors may favor 
Colesonline while some prefer Shopfast. Due to the provision of the Customer Care Centre by Colesonline and the fact that it is operated by one of the largest retail chains in Australia, Colesonline was rated very high for the 'Trustworthiness of the Web Site' criterion. In addition, Colesonline offers a personal shopping list to consumers and therefore received the highest rating for the personalization function.

Figure 3 compares the assessment figures with the perceived user expectations for both the Best Practice and Sector Profiles. The ideal situation is achieved when all the categories lie on or above the diagonal as shown on the figure. Consistent with the above findings, the figure depicts that for Colesonline, three phases including the Agreement Phase, After-Sales Phase and Final Section lie exactly on the diagonal and they are within the "Maintain Strategy' zone. This indicates that these three categories have a good performance, as the users' expectation meet the actual assessment. Two other items, the Information and Settlement Phases, are below the diagonal but still within the 'Maintain Strategy' zone. A further analysis indicates that Colesonline particularly has a high performance for Accessibility of the web site and Products (scored at 1.73), Quality of the Content (1.26), Models and Method of Pricing (1.16), Access to Customer Support (1.16), Availability of the System (1.45) and Trustworthiness of the web site (1.40). The community component of Colesonline, however, has a reasonably good performance, although this component is not considered as important. Therefore, this item lies on the 'Strategic Overkill' zone in Figure 3. These findings are consistent with the qualitative analysis.
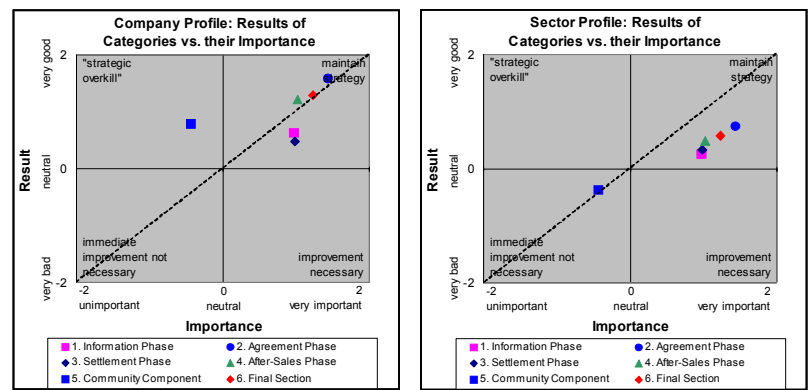

Figure 3. Strategy Evaluation for the Best Practice and Sector Profile (Australia)

In regard to the Sector profile, all items except for the community component are situated in the 'Maintain Strategy' zone, but they are quite far below the diagonal. This implies that there are still opportunities to improve most of the Australia web sites in the grocery sector, although the sites have a reasonable performance. The community component lies on the diagonal and is situated in the 'Immediate Improvement not Necessary" zone. This means that although the community component of the Sector profile does not have a high score, it was not rated as as important either. Therefore, no immediate improvement is required for this.

In summary, based on the results of the web evaluation of the Australian sites, the study reveals that the majority of the web sites still require some improvements in many areas as they still lack behind the performance of the Best Practice Company. This lack of maturity of web sites in this sector could attribute to the slow acceptance of the online grocery shopping in Australia, among other factors. Therefore, by improving the web sites particularly in the specific areas identified in this study, the acceptance of online grocery shopping by the Australian consumers could likely be improved.

\subsection{Swiss Results}

In this sector, four Swiss web sites were assessed which included:

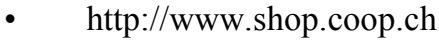

- $h t t p: / / w w w . l e s h o p . c h$

- $\quad$ http://www.migros-shop.ch

- $\quad h t t p: / / w w w . s p a r . c h$

The selected Swiss online shops included the two large Swiss retailers Coop and Migros, the shop of the SparGroup Switzerland and the shop of a Swiss grocery group called Bon appétit Groupe AG (LeShop). Coop, Migros and Spar operate a close-meshed grid of physical stores and offer online shopping as an additional customer service. In contrast to this, LeShop is a pure online player and was the first company offering grocery products online in Switzerland.

Since the time of data collection of the Swiss grocery stores in the spring of 2002, the Swiss online market has seen some important changes. Firstly, Spar shut down its online shop in August 2002 for a lack of demand, while LeShop was sold to private investors at the end of 2002. Then, at the beginning of the year 2004, LeShop almost had to shut down its operations but was rescued by a group of investors. A couple of months later, LeShop and Migros merged into one joint online store which is run by the former LeShop crew at the time of writing this article.

Figure 4 depicts the summary of the overall evaluation of the web sites included in the Swiss grocery sector. As shown in the figure, Migros appears to be the best site in the sector, whereas the Spar web site has the worst evaluation result. Other web sites require significant improvements in order to achieve a comparable quality web site as Migros, which is the best practice web site in this sector.

The two large-scale companies Migros and Coop nearly reached the same overall result. The customer choice between these two shops likely depends on personal preferences towards the real-world brand (the vendor), product range, and price level. In Switzerland, a kind of "religious war" between Migros and Coop follow- 
ers can be observed which seems to also translate to the online realm.

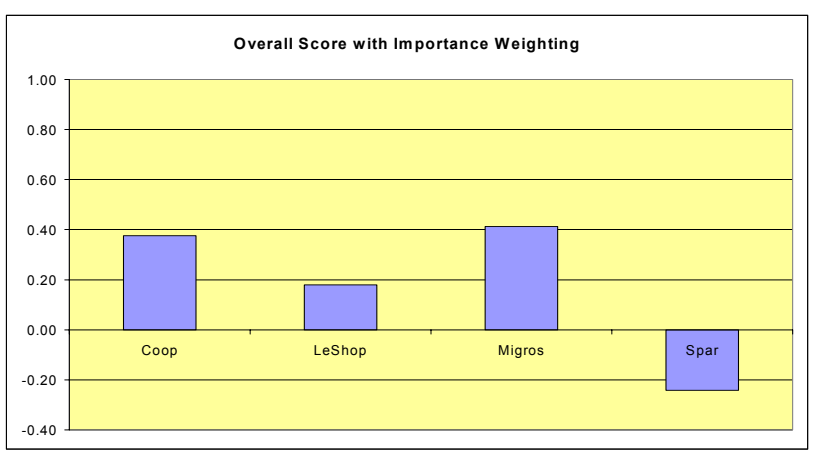

Figure 4. The Summary of the Overall Web Evaluation (Switzerland)

Figure 5 summarizes the company profile for all web sites evaluated in this study, indicating the score obtained in each phase. It shows that in Switzerland, the Best Practice Company does not stand out as much as it does in Australia. The companies were more evenly rated.

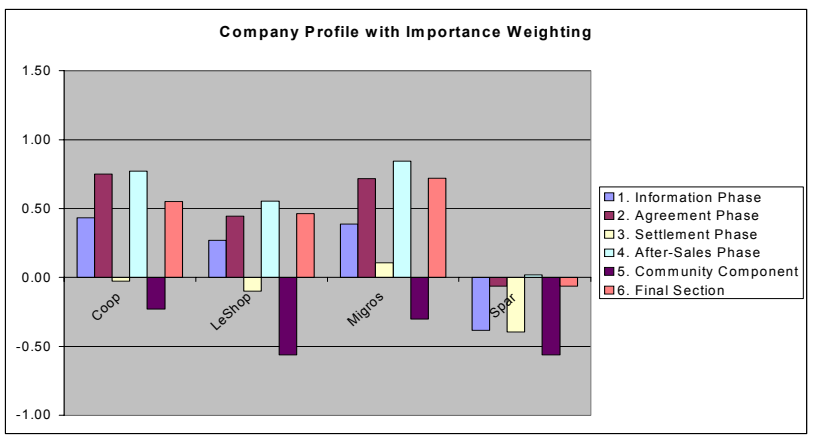

Figure 5. Summary of the Company Profile (Switzerland)

Overall, the Swiss results are better than the Australian results. Most participants seem to be satisfied with the sites in general. These observations were confirmed by the subsequent qualitative analyses conducted by the authors as well as the qualitative remarks supplied by the Swiss assessors.

In the Information Phase the analyzed web sites show varying results. Important criteria in this phase are the possibility of finding and locating the web site, the presentation of products, information about special offers and the quality and quantity of the information provided.

All four Swiss web sites can be found easily on the web. The assessors criticized that the two leaders in the retail sector, Migros and Coop, do not point out the existence of an online shop on their general company web site. They recommended that LeShop as a pure online player should work harder to move to a higher place in search engines because as a pure online shop it has not got the same name recognition as the other three retailers.
In the shops of Coop, Migros and LeShop, the range is presented very "originally and clearly". Products are arranged with reference to product categories or in the same order as in the physical stores. Migros and Coop give detailed descriptions of the products, which was positively emphasized by the assessors. Nearly all products are illustrated with graphics which facilitates the recognition for inexperienced shoppers. Spar, on the other hand, does not offer pictures; this fact was often mentioned as missing and "rather boring". Information about delivery time is given by all web shops.

The navigation within the web sites of Coop, Migros and LeShop is easy, clear and logically built. The Spar web site is confusing and it was even described as "malicious" by one of the assessors.

For the Agreement Phase the shops of Migros, Coop and LeShop received a good evaluation. The ordering process is transparent and interactive. LeShop offers the possibility of payment by invoice and bank transfer, while Coop even offers the possibility of cash payment. The assessors welcome the choice between these three payment methods. The results of Spar differ: Some assessors praise the "clear and simple" structure of the payment process, while others describe "the navigation and subnavigation [as] not well designed". Moreover, some of the virtual sections did not contain any products.

In the Migros shop, customers are able to define a personal shopping list which is very helpful in selecting every day items. Coop additionally makes the customers shopping proposals based on the transaction profiles.

Furthermore, it has to be mentioned that buying grocery products online does not lead to direct price advantages for the customer. The shipping costs are reduced or dropped if a purchase reaches a certain amount saves the customer from walking to the store and fetching his purchase personally.

For the Settlement Phase, in all shops - except Coop, where cash payment is possible - payment has to be done in advance by credit card or bank transfer or later by invoice. Payment by credit card is the most widely used method in Swiss online shopping in general. The assessors do not criticize it but they also do not praise it as a particularly beneficial payment method.

Coop allows for a very precise selection of the delivery time (+/- 30 minutes). In contrast, Migros indicates a large-scale delivery period which was criticized by the assessors. On the other hand, they appreciate the short delivery time provided by Migros: depending on the delivery region orders can be placed until 10.00 in the morning and the goods will be delivered shortly after 4.00 p.m. on the same day. LeShop offers a longer delivery period because delivery is limited by the service of the Swiss postal service (LeShop's fulfillment partner). Spar delivers within a period of three hours by courier but only within very limited delivery areas. The charge for deliv- 
ery (between 10 and 15 Swiss Francs) was acceptable for the assessors.

Migros is the only vendor who offers the order tracking facility. Since this function is not considered as very important, the assessors do not criticize the lack of this function in the other shops. In the grocery sector purchase order tracking seems to be a so called "nice-to-have" feature which does not lead to a real advantage for the customer.

For the After-Sales Phase only few comments were made. This is a positive result because the assessors had to use the customer service very rarely. In those cases where calling the customer service was necessary, assessors praised the "friendly and competent telephone support" (provided by LeShop). One example was a question for the LeShop customer support regarding the handling and the return of delivery boxes for which a deposit had to be paid.

In the case of Coop and Migros customers appreciated the integration of the pay back programs ("SuperCard" and "Cumulus") into the online shop. This makes it possible to collect shopping points no matter which channel (electronic or brick-and-mortar) a customer is using.

For low quality products and for products which do not meet customer expectations completely, LeShop offers a money back strategy. This offer is very helpful to ensure that only quality and fresh products are delivered.

Calling the customer service by phone or e-mail will be unavoidable if the customer forgets his password. It is found a nuisance that in all evaluated shops the customer service is only available during (extended) business hours. For the customer who wants to shop late in the evening this is not very helpful.

Looking at the importance of the EWAM criteria it becomes obvious that the Community Component is not very important in the grocery sector. Accordingly, the number of comments regarding the community component was very low. The assessors did not expect community functions.

For the Final Section, Migros once again received the highest rating. User guidance is intuitive und well structured in all evaluated shops. The graphical design of the user interface is a matter of taste. The assessors repeatedly praised the facility to overview of the purchase orders at the end of the shopping process on the LeShop web site. In the case of Coop and Migros some assessors felt insecure during the payment process because the payment module does not appear in the same look and feel as the other pages of the shop.

All vendors make little use of the possibilities for hyperlinks. The presentation of suitable recipes, the offer of a nutrition consultation or search possibilities for further information do exist but they appear to be copied from a paper version of the product catalog.

In the shops of Coop and Migros, the trisection of the screen into range, product, and shopping cart was rated as good. The permanent display of the shopping cart as well as the possibilities to change its contents in the shops of Coop, LeShop and Migros were positively noted. In these three shops it is also possible to save a personal shopping cart and to open it again if required and generate a new purchase order from it. The assessors rate this personalization method as very useful.

Further differences between the analyzed online shops can be observed in the area of trustworthiness of the shops. The high trustworthiness of Coop and Migros is based on the high name recognition of these two since they are established vendors for decades. Le Shop, on the other hand, as a young and pure online grocer, first had to stand the test on the market for grocery products.
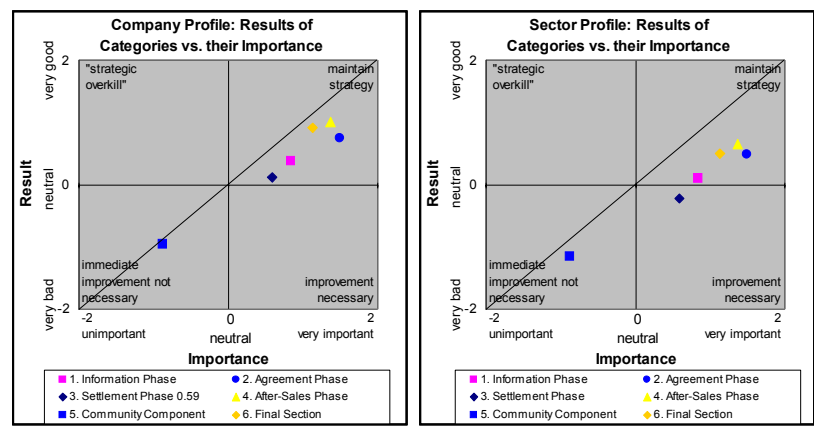

Figure 6. Strategy Evaluation for the Best Practice and Sector Profile (Switzerland)

Figure 6 shows a comparison of the Best Practice example of Migros with the average Sector Profile. In regard to the Sector profile, all items except for the community component are situated in the 'Maintain Strategy' zone, but they are slightly below the diagonal. This implies that there are still opportunities for an average improvement of Swiss web sites in the grocery sector.

Looking at the details of the study, the results show that the more important phases are better realized than the less important ones in all shops. This is an indication that Swiss online merchants have a pretty good idea of what is important for their clientele. The position in regard to the diagonal varies highly among the different shops. The further away from the diagonal the values are, the greater the disproportion between the target value (importance rating) and the conceived situation (assessment rating). This is most noticeable for Spar, where almost all elements are in the lower right quadrant.

In summary, based on the results of the web evaluation of the Swiss sites, the study reveals that the majority of the web sites do meet user expectations up to a certain point. The Best Practice Company does not stand out as far as in the Australian sample. 


\section{Comparative Analysis and Findings}

Using the EWAM tool, this study indicates that online grocers in Australia and Switzerland have not fully met the expectations of consumers. The study further shows that the performance of Swiss online grocers in various transaction phases has been more consistent across the sample sites compared to the Australian case. In Australia, the best practice site was rated much higher than other sites in almost all transaction phases.

Although Australia and Switzerland differ in many respects, the results of the study demonstrate that consumers' expectations in online grocery shopping are consistent in both regions. The study shows the importance of having a pleasant, easy-to-use user interface with no information overload on the pages. Furthermore, the availability of the images of products was found to be important in the Information Phase. Both studies also indicate the importance of having a good position in search engines, particularly for pure online players.

The analysis of the importance ratings also indicates that the importance varies among the different phases and components of the transaction process. Other studies showed that these ratings also vary between different industries [21]. In order to improve the design of a web site it could be useful to analyze the importance rating in the relevant sector and concentrate design activities on the most important phases or on specific criteria.

For the Agreement phase, the studies demonstrate the importance of having a transparent ordering procedure and a clear status of the purchase process at any time.

For the Settlement Phase, the choice of preferred payment method is crucial. Credit card, customer account, cash or cheque upon delivery should be accepted. The ability to track and trace orders is considered to be a 'nice to have' feature but may not be necessary as demonstrated by the Swiss study. However, precise selection of the delivery date and time is important in both cases.

The importance of the Settlement Phase was rated higher in the Australian study than in Switzerland. Since Australia is a big continent and everything is spread over a relatively larger geographic location than in Switzerland, it would be more important for consumers in Australia to be able to track their orders as well as to be informed about the exact delivery time so that they can plan their activities accordingly. It would be more troublesome for customers in Australia than in Switzerland, to return products, for example, because of the geographical factor.

For the After-Sales Phase, both studies show the importance of having an online Customer Care Centre (as in the case of Colesonline) with a contact number as well as the details of the opening hours.

Finally, for the Final Section, this study shows that trustworthiness of the sites plays a crucial role. Colesonline, which is operated by one of the largest retail chains in Australia, and Coop and Migros which have a high name recognition because they are established Swiss vendors, received high rating in general. The study further shows that customers appreciate the integration of brickand-mortar pay back programs ("SuperCard" and "Cumulus" demonstrated in the Switzerland study) into the online shop. Last but not least, the ability for consumers to recall their personal shopping list for consecutive sessions was found to be an attractive and useful feature.

Most online grocers evaluated in this study still need to better understand and be aware of all of the above expectations of consumers in order to improve their web sites in the various phases of the buying process.

\section{Conclusions and Limitations to this Study}

EWAM is one of the oldest evaluation methods of its kind. It lays down a conceptual framework for the evaluation of commercial web sites that in its basic form, the Web Assessment Method, has already proved itself in operation for several years. In this study, we have demonstrated the usefulness of the EWAM tool in assessing various Swiss and Australian web sites within the grocery sector. Strengths and weaknesses of various web sites of Australian and Swiss grocers have been highlighted. As discussed comprehensively in the previous sections, most of the web sites in both countries still lack an acceptable degree of sophistication. Their designers still need to better understand consumers' expectations and improve the performance of their web sites accordingly in order to increase the satisfaction level of consumers. This in turn can accelerate the use of online shopping. However, due to the specific nature of grocery items in which they are perishable, bulky, ordered frequently, and needed urgently, combined with issues related to storage, picking, packing and health, the web sites facilitating online grocery shopping have to be designed very carefully to ensure that consumers are confident with the overall procedure.

In this study, we have also demonstrated that web assessment is very ambitious and labor-intensive work. There are a number of requirements that the assessors have to meet in conducting a web assessment using the EWAM tool:

1. They need to fully understand the criteria of the Web assessment form and thus must be thoroughly instructed.

2. They must be experienced Web users.

3. They must take the time to go through all four transaction phases for each web site assessed (including delivery and payment!).

An empirical study with a limited sample set, such as this study, can only reflect a partial and somewhat biased picture of current practice in the analyzed sector. The bias exists because the students share similar opinions of ecommerce and they are homogeneous (since they attended the same electronic commerce class, their opinions tend to 
be less universal than if they were hand-picked at random). Furthermore, the participants of this study are not representative of the hundred thousands of web users in Australia and Switzerland. Nevertheless, since the EWAM tool is a highly knowledge-requiring process, one cannot ask a random sample of people to do the assessments. In addition, although the web sites chosen for evaluation were not very diverse the number of serious players in the online world is still limited. Therefore, the limited number of participants and the web sites assessed in this study should not invalidate the findings obtained. These findings have been confirmed by the subsequent qualitative evaluations as described in this paper.

\section{References}

[1] Barnett, M. and P. Alexander, "Can e-Grocers Survive the Last Mile", 4th International We-B Conference, Perth, Western Australia, 2003.

[2] Morganosky, M. and B. Cude, "Consumer Response to Online Grocery Shopping", International Journal of Retail and Distribution Management, 28 (1), (2000), pp 17-26.

[3] Mahajan, V.; Srinivasan, R., "The Dot.com Retail Failures of 2000: Were there Any Winners?", Journal of the Academy of Marketing Science, 30 (4), 2002, pp. 474486.

[4] Schubert, Petra, "Extended Web Assessment Method (EWAM) - Evaluation of Electronic Commerce Applications from the Customer's Viewpoint", International Journal of Electronic Commerce, Vol. 7, No. 2, Winter 2002-2003, pp. 51-80.

[5] Spiliopoulou, Myra, "Web Usage Mining for Web Site Evaluation, in: Communications of the ACM" (CACM), Vol. 43, Nr. 8, August 2000, S. pp. 127-134.

[6] Barnes, Stuart J.; Vidgen, Richard, "An Evaluation of Cyber-Bookshops: The WebQual Method", International Journal of Electronic Commerce, Volume 6, Number 1, Fall 2001.

[7] Barnes, Stuart J.; Vidgen, Richard, "An Evaluation of Cyber-Bookshops: The WebQual Method", International Journal of Electronic Commerce, 6 (1) Fall 2001.

[8] Koufaris, Marios., "Applying the Technology Acceptance Model and Flow Theory to Online Consumer Behavior", Information Systems Research, 13 (2), 2002, pp. 205-223.

[9] Anderson, E. J.; Philpott, A. B.; Discenza, Joseph H.; Haley, K. Brian; Palmer, Jonathan W., "Web Site Usability, Design, and Performance Metrics", Information Systems Research, 13 (2), 2002, pp. 151-167.

[10] Devaraj, Sarv; Fan, Ming; Kohli, Rajiv, "Antecedents of B2c Channel Satisfaction and Preference: Validating E-Commerce Metrics", Information Systems Research, 13 (3), 2002, pp. 316-333.

[11] Davis, Fred D. Jr., “A Technology Acceptance Model for Empirically Testing New End-User Information Sys- tems: Theory and Results", Doctoral Thesis, Sloan School of Management: Massachusetts Institute of Technology, 1985.

[12]Fishbein, M.; Ajzen, I., "Belief, Attitude, Intention and Behavior: An Introduction to Theory and Research", Reading, MA: Addison-Wesley, 1975.

[13] Parasuraman, A.; Zeithaml, Valerie; Berry, Leonard "SERVQUAL: A Multi-item Scale for Measuring Consumer Perceptions of Service Quality", Journal of Retailing, Vol. 64 (1) S, 1988, pp. 12-40.

[14] Kinsey, J. and B. Senauer, "Consumer Trends and Changing Food Retailing Formats." American Journal of Agricultural Economics 78 (5), 1996, pp 1187-91.

[15] Schuster, A. and B. Sporn, "Potential for Online Grocery Shopping in the Urban Area of Vienna." Journal of Electronic Market 8 (2), 1998.

[16] Kurnia, S. and J. A.-W. Chien, "The Acceptance of the Online Grocery Shopping", The 16th Bled Electronic Commerce Conference, Bled, Slovenia, 2003.

[17] Moser, U. and P. Schubert 2003, „Payment Methods for Online Shops: A study about their application in Switzerland and criteria for their selection", original title: „Zahlungsmethoden für Online-Shops: Eine Studie zum Einsatz in der Schweiz und daraus abgeleitete Entscheidungskriterien für die Auswahl“", Basel: University of Applied Sciences Basel, Institute for Business Economics, Working Paper E-Business No. 17, 2003.

[18] Selz, D. and Schubert, P.: Web Assessment - A Model for the Evaluation and Assessment of successful Electronic Commerce Applications, in: Proceedings of the 31st HICSS Conference, Hawaii, 1998, pp. 222-231.

[19] Schubert, P. and Selz, D.: Web Assessment - Measuring the Effectiveness of Electronic Commerce Sites Going Beyond Traditional Marketing Paradigms, in: Proceedings of the 32nd HICSS Conference, 1999.

[20] Schubert, P.: Extended Web Assessment Method (EWAM) - Evaluation of Electronic Commerce Applications from the Customer's Viewpoint, International Journal of Electronic Commerce, Vol. 7, No. 2, Winter 20022003, pp. 51-80.

[21] Schubert, P. and Dettling, W.: Web site evaluation: Do Web applications meet user expectations? Music, consumer goods and e-banking on the test bed, in: Proceedings of the 14th International Bled Electronic Commerce Conference, 2001. 